\title{
Pattern of snakebite cases evaluated at a tertiary care hospital
}

\author{
Kashif Ali ${ }^{1, *}$, Ishan Pathak ${ }^{2}$, Sheetal Sehrawat ${ }^{3}$ \\ ${ }^{\mathbf{1}}$ Postgraduate, ${ }^{\mathbf{2}}$ Assistant Professor, ${ }^{3}$ Undergraduate, ${ }^{\mathbf{1}, \mathbf{3}}$ Dept. of Forensic Medicine \& Toxicology, ${ }^{2}$ Dept. of Community Medicine, ${ }^{\mathbf{1}, 3} \mathrm{~J} . \mathrm{N}$. \\ Medical College, Belagavi, Karnataka, ${ }^{2}$ DM-Wayanad Institute of Medical Sciences, Meppadi, Kerala, India
}

*Corresponding Author: Kashif Ali

Email: alikashif568@yahoo.in

\begin{abstract}
Introduction: Snakebite is a serious public health issue worldwide especially in Indian subcontinent. The high mortality in India is due to climatic factors, rural predominance of population and their agricultural dependence. It is a neglected disease that usually affects the rural inhabitants indulging in agricultural activities. All snakes are tabooed for being deadly poisonous but truth is miles away as majority of them belongs to non-poisonous category.

Objective: To study the pattern of Snakebite cases evaluated at KLE Hospital of J.N. Medical College, Belagavi, Karnataka.

Study Design: A retrospective hospital record based study.

Materials and Methods: The study was done by analyzing the case records at Medical Record Department of J.N. Medical College, Belagavi, Karnataka for all patients admitted with Snakebite envenomation from January 2013 to December 2017. Relevant information was entered in a pre-structured proforma which include age, sex, site of bite, place of residence, occupation, season and time of bite and mortality. All the patients who came to hospital with the history of Snakebite were included in the study.

Results: There was total 143 Snake bite cases among which $89(62.2 \%)$ were males and $54(37.8 \%)$ were females. The highest incidence of Snake bite was observed in age group of 20-29 years (29.4\%). The majority of the victims belonged to rural areas 107 (74.8\%) as compared to urban areas $36(25.2 \%)$. The most vulnerable occupation group was the people involved in the agricultural activities $85(59.4 \%)$. The maximum number of snake bite cases was reported during the rainy season $(40.6 \%) .117(81.8 \%)$ patients were bitten by venomous snakes as compared to 26 patients (18.2\%) which were bitten by non-venomous snakes.

Conclusion: Snakebite is a matter of great concern as it is one of the neglected health problems. It is a need of hour to educate the community about the prevention of snakebite, early hospitalization and first aid measures by which there will be drastic fall in snakebite cases.
\end{abstract}

Keywords: Snake bite, Pattern, Snake, Rural, Anti snake venom.

\section{Introduction}

Snakebite is a serious public health issue worldwide especially in Indian subcontinent. In India the mortality due to venomous snake bite is $35000-50000$ per annum according to WHO (World Health Organization). ${ }^{1}$ Snake bite cases are recently included in the list of neglected tropical diseases as per WHO (World Health Organization) and it could be the most neglected of all the diseases in the $21^{\text {st }}$ century. ${ }^{2}$ Snake bite is one of the major life threatening problems all over the world which may cause local to systemic complications in the form of neurotoxicity, haematotoxicity or myotoxicity. All snakes are tabooed for being deadly poisonous but truth is miles away as majority of them belongs to non-poisonous category. People in countries like India still prefer the traditional healers rather than trained doctors mainly because of their great belief in voodoos and due to illiteracy, ignorance and lack of knowledge.

Usually poisonous snakes are nocturnal with small head scales while their belly scales are large covering the entire breadth with compressed tail and 2 long fangs. On contrary, the non-poisonous snakes have large head scales with small belly scales partially covering the breadth with comparatively less compressed tail and several small teeth. Snake venom is a toxic saliva secreted by the modified parotid salivary gland. The increased mortality and morbidity is due to the inadequate training of the primary level health workers, scarcity of anti-snake venoms, improper first aid measures, delay in transport and poor quality of healthcare services.

The only specific antidote treatment available for snakebite envenomation is Anti Snake venom (ASV). The antisnake venom is classified on the basis of species covered into monovalent and polyvalent. The monovalent antisnake venom can counteract against the bite of a single species while the polyvalent antisnake venom is effective against multiple snake species. In India the available antisnake venom covers only the "Big Four" species i.e. Common Cobra, Common Krait, Russel's viper and Saw scaled viper. The best treatment for any snakebite case is the early administration of antisnake venom which is beneficial in preventing complications as well as morbidity. The current study was conducted to assess and analyze the epidemiological profile and outcome of snakebite victims admitted to a tertiary care hospital.

\section{Materials and Methods}

The study was done by analyzing the case records at Medical Record Department of J.N. Medical College, Belagavi, Karnataka for all the patients admitted with snakebite envenomation from January 2013 to December 2017. Relevant information was entered in a pre-structured proforma which include age, sex, site of bite, place of residence, occupation, season and time of bite and mortality. All the patients who came to hospital with the history of snakebite were included in the study. 


\section{Results}

A total of 143 snake bite cases among which 89 $(62.2 \%)$ were males and $54(37.8 \%)$ were females. The highest incidence of snake bite was observed in age group of $20-29$ years $(29.4 \%)$ followed by $40-49$ years $(21.7 \%)$ and least in $0-10$ years $(4.9 \%)$ as shown in Table 1 . The majority of victims belonged to rural areas $107(74.8 \%)$ as compared to urban areas $36(25.2 \%)$. The most vulnerable occupation group was the people involved in agricultural activities 85 (59.4\%) followed by housewives 26 (18.2\%) and students $21(14.7 \%)$ as shown in Table 2.

$96(67.1 \%)$ victims were bitten during the night as compared to $47(32.9 \%)$ during the day time (as shown in Table 3). The maximum numbers of cases were reported during the rainy season $(40.6 \%)$ as compared to other seasons which is depicted in Table 4. According to Table 5, $103(72 \%)$ cases were bitten on lower extremity followed by $35(24.5 \%)$ on upper extremity, $3(2.1 \%)$ on the trunk and 2 $(1.4 \%)$ on head and neck. $117(81.8 \%)$ patients were bitten by venomous snakes as compared to 26 patients $(18.2 \%)$ which were bitten by non-venomous snakes as depicted in Table 6. Among 117 venomous snake bites, 17 patients expired during the hospital stay.

Table 1: Distribution of cases according to age and sex

\begin{tabular}{|l|c|c|c|c|}
\hline $\begin{array}{c}\text { Age } \\
\text { Group }\end{array}$ & Male & Female & $\begin{array}{c}\text { Total number } \\
\text { of cases }\end{array}$ & Percentage \\
\hline$<10$ & 04 & 03 & 07 & 4.9 \\
\hline $11-19$ & 17 & 12 & 29 & 20.2 \\
\hline $20-29$ & 24 & 18 & 42 & 29.4 \\
\hline $30-39$ & 16 & 06 & 22 & 15.4 \\
\hline $40-49$ & 20 & 11 & 31 & 21.7 \\
\hline$>50$ & 08 & 04 & 12 & 8.4 \\
\hline Total & 89 & 54 & 143 & 100 \\
\hline
\end{tabular}

Table 2: Distribution of cases according to occupation

\begin{tabular}{|l|c|c|}
\hline Occupation & Number of cases & Percentage \\
\hline Farmer & 85 & 59.4 \\
\hline Housewife & 26 & 18.2 \\
\hline Student & 21 & 14.7 \\
\hline Others & 11 & 7.7 \\
\hline Total & 143 & 100 \\
\hline
\end{tabular}

Table 3: Distribution of cases according to time of bite

\begin{tabular}{|l|c|c|}
\hline Time & Number of cases & Percentage \\
\hline Day time & 47 & 32.9 \\
\hline Night time & 96 & 67.1 \\
\hline Total & 143 & 100 \\
\hline
\end{tabular}

Table 4: Distribution of cases according to season

\begin{tabular}{|l|c|c|}
\hline Season & Number of cases & Percentage \\
\hline Summer & 33 & 23.1 \\
\hline Rainy & 58 & 40.6 \\
\hline Winter & 52 & 36.3 \\
\hline Total & 143 & 100 \\
\hline
\end{tabular}

Table 5: Distribution of cases according to site of snakebite

\begin{tabular}{|l|c|c|}
\hline Place of bite & Number of cases & Percentage \\
\hline Lower limb & 103 & 72 \\
\hline Upper limb & 35 & 24.5 \\
\hline Trunk & 03 & 2.1 \\
\hline Head and Neck & 02 & 1.4 \\
\hline Total & 143 & 100 \\
\hline
\end{tabular}

Table 6: Distribution of cases according to venomosity and mortality

\begin{tabular}{|l|c|c|c|c|}
\hline \multicolumn{1}{|c|}{ Type of Snake } & Number of cases & Percentage & Mortality & Percentage \\
\hline Venomous & 117 & 81.8 & 17 & 100 \\
\hline Non-venomous & 26 & 18.2 & 0 & 0 \\
\hline Total & 143 & 100 & 17 & 100 \\
\hline
\end{tabular}

\section{Discussion}

In the present study, $89(62.2 \%)$ patients were male victims whereas the female victims were $54(37.7 \%)$ in number. The male victims outnumbered the female victims because the males are more indulged in outdoor activities, agricultural and field work. This is consistent to the studies done by Jarwani et $\mathrm{al}^{3}$ and Brunda et $\mathrm{al}^{4}{ }^{4}$ The higher incidence of snakebites were observed in the age group of 20-29 years $(29.4 \%)$ followed by $40-49$ years $(21.7 \%)$ and $11-19$ years $(20.2 \%)$ which is similar to the study done by Lal et al. ${ }^{5}$ Snakebite is more common in younger age group as they are involved in agricultural activities and are risk takers.

The majority of victims belonged to rural areas (74.8\%) as compared to urban areas $(25.2 \%)$ as the snakes are in abundance in rural areas and the people living there come across snakes in their life very often due to their living conditions, habits, working and walking bare footed. The most vulnerable occupation group was the people involved in agricultural activities (59.4\%) followed by housewives (18.2\%) and students (14.7\%) which is similar to studies done by Logaraj et $\mathrm{al}^{6}$ and Anjum et al. ${ }^{7}$ This is because still the farmers and laborers are not using good protective shoes, etc., for their safety. The most common site of the bite was lower extremities (72\%) followed by upper extremities (24.5\%). This finding suggests that the site of snakebite is predominantly determined by accidental or inadvertent contact of the reptile during the activity. This is comparable to the studies done by Thapar et al, ${ }^{8}$ Shetty et $\mathrm{al}^{9}$ and Monteiro et al. ${ }^{10}$

The maximum number of snakebite cases was reported during the rainy season $(40.6 \%)$ because of the flooding of 
the habitats of the snakes and other rodents and insects are more during this time. The majority of victims were bitten during night time $(67.1 \%)$ as compared to day time $(32.9 \%)$ which is similar to findings reported by Logaraj et $\mathrm{al}^{6}$ and Sharma et al. ${ }^{11}$ Snakebites are more common during night and in poor lighting conditions where people inadvertently step on the snakes. $117(81.8 \%)$ patients were bitten by venomous snakes as compared to 26 patients (18.2\%) which were bitten by non-venomous snakes and among these 117 venomous snake bites, 17 patients expired during the hospital stay which is similar to the study conducted by Nagaraju et al. ${ }^{12}$

\section{Conclusion}

It is a need of hour to impart knowledge regarding the prevention of snake bite, early hospitalization and the first aid measures to the young people, rural farmers and field workers as they are more prone to snake bite. In poisonous snake bite, early administration of ASV (Anti Snake venom) will result in less complications and mortalities. Most of the reported snakebite cases are due to non-poisonous bites which need only reassurance and first aid. It is necessary to educate the people about the poisonous and non-poisonous snake bites through community health programs. According to this study, the snake bites were more common in rural areas and among people who are engaged in agricultural activities, so health education programs should be conducted to enlighten the rural farmers towards the use of boots to prevent snakebite. Along with this the Primary Health Centres (PHC) and Rural Health Training Centres (RHTC) should always be fully equipped with facilities to give first aid measures and administer antisnake venom if required.

\section{Conflict of Interest: None}

\section{Source of Funding: Self-funded}

Ethical Clearance: Taken from Institutional Ethics Committee

\section{References}

1. Mohapatra B, Warrell DA, Suraweera W. Snakebite Mortality in India: A Nationally Representative Mortality Survey. PLoS Negl Trop Dis. 2011;5(4):e1018.

2. World Health Organization. Neglected Tropical Diseases 2017. Available from: http://www.who.int/neglected_diseases/snakebites

3. Jarwani B, Jadav P, Madaiya M. Demographic, epidemiologic and clinical profile of Snakebite cases presented to Emergency Medicine department, Ahmedabad, Gujarat. J Emerg Trauma Shock. 2013;6:199-202.

4. Brunda G, Sashidhar RB. Epidemiological profile of snakebite cases from Andhra Pradesh using immunoanalytical approach. Indian J Med Res. 2007;125:661-668.

5. Lal P, Dutta S, Rotli SB, Danabalan M, Kumar A. Epidemiology profile of snakebite cases admitted in JIPMER. Indian J Community Med. 2001;26:36-38.

6. Logaraj M, Thirumavalavan R, Gopalakrishnan S. Epidemiology of snakebite reported in a Medical College Hospital in Tamil Nadu. Int J Health Allied Sci. 2013;2:53-55.
7. Anjum A, Husain M, Hanif SA. Epidemiological Profile of Snakebite at Tertiary care Hospital, North India. J Forensic Res. 2012;3:146.

8. Thapar R, Darshan BB, Unnikrishnan B. ClinicoEpidemiological Profile of Snakebite cases admitted in a Tertiary care Centre in South India: A 5 Years Study. Toxicol Int. 2015;22(1):66-70.

9. Shetty AK, Jirli PS. Incidence of Snakebites in Belgaum. $J$ Indian Acad Forensic Med. 2010;8:139-141.

10. Monteiro FN, Kanchan T, Bhagavath P, Kumar GP. Krait bite poisoning in Manipal region of Southern India. J Indian Acad Forensic Med. 2011;33:43-45.

11. Sharma N, Chauhan S, Faruqi S, Bhat P, Varma S. Snake envenomation in a North Indian Hospital. Emerg Med J. 2005;22:118-120.

12. Nagaraju K, Kannappan N, Gopinath K. Survey on Pattern of snake bite cases admitted in South Indian tertiary care Hospital. Int J Pharm Sci Res. 2015;6(10):4362-4367.

How to cite this article: Ali K, Pathak I, Sehrawat S. Pattern of snakebite cases evaluated at a tertiary care hospital. Indian J Forensic Community Med. 2018;5(4):215-217. 